\title{
Comparison of the accuracy of the hemocue glucose analyzer with the Yellow Springs Instrument glucose oxidase analyzer, particularly in hypoglycemia
}

\author{
Alexander D M Stork, Hans Kemperman ${ }^{1}$, D Willem Erkelens and Thiemo F Veneman ${ }^{2}$ \\ Department of Internal Medicine and Metabolic Diseases and ${ }^{1}$ Department of Clinical Chemistry, University Medical Center Utrecht, Utrecht, \\ The Netherlands and ${ }^{2}$ Department of Internal Medicine, Twenteborg Hospital, Almelo, The Netherlands \\ (Correspondence should be addressed to A D M Stork, University Medical Center Utrecht, Department of Internal Medicine and Metabolic Diseases, \\ 31 Puttershof, 3451 LC Vleuten, The Netherlands; Email: adm.stork@hccnet.nl)
}

\begin{abstract}
Objective: We aimed to assess the accuracy of the HemoCue Beta-glucose analyzer (HemoCue) and its correlation with the Yellow Springs Instrument (YSI 2300 STAT; YSI) glucose oxidase analyzer, in particular for hypoglycemic values.

Design and methods: Samples were taken from 24 volunteers during hyperinsulinemic glucose clamp studies. Glucose concentrations were determined immediately with the HemoCue in whole blood and with the YSI in plasma from the same sample. After correction for the difference between whole blood and plasma, the paired plasma glucose concentrations were analyzed with various statistical methods.

Results: A total of 500 paired glucose values were obtained, 209 of which were in the hypoglycemic range. Mean \pm S.E. values were $4.85 \pm 0.004 \mathrm{mmol} / \mathrm{l}$ for the HemoCue (range 1.87-16.17) and $4.81 \pm 0.004 \mathrm{mmol} / \mathrm{l}$ for the YSI (range 1.88-15.00; $P=0.80$ ). In the hypoglycemic region, values were $3.26 \pm 0.004 \mathrm{mmol} / \mathrm{l}$ for the HemoCue (range $1.87-5.17$ ) and $3.22 \pm 0.003 \mathrm{mmol} / \mathrm{l}$ for the YSI (range 1.88-4.20; $P=0.59$ ). Regression analyses were HemoCue $=1.019(\mathrm{YSI})-0.0577 \mathrm{mmol} / \mathrm{l}$, with $r=0.9787$ for all values; for hypoglycemic values the HemoCue $=1.1169$ (YSI) $-0.3393 \mathrm{mmol} / \mathrm{l}$, with $r=0.8798$. Using Altman's residual plot, the difference was $0.03 \pm 0.0009 \mathrm{mmol} / \mathrm{l}$, with $18(3.6 \%)$ paired values outside the $95 \%$ limits of agreement $(-0.82$ to $0.89 \mathrm{mmol} / \mathrm{l})$. In the hypoglycemic range, the difference was $0.04 \pm 0.001 \mathrm{mmol} / \mathrm{l}$, with six $(2.9 \%)$ values outside the $95 \%$ limits of agreement $(-0.71$ to $0.79 \mathrm{mmol} / \mathrm{l})$. In error grid analysis, one value was in zone $\mathrm{D}(0.2 \%)$ and five values $(1 \%)$ were in zone $\mathrm{B} ; 98.8 \%$ were within zone A.

Conclusions: Determination of glucose with the HemoCue system had very good correlation with the YSI system in a broad range of glycemia and also for hypoglycemic values. We believe that these methods can be used interchangeably for research and clinical purposes in adults.
\end{abstract}

European Journal of Endocrinology 153 275-281

\section{Introduction}

The incidence and prevalence of type 1 and type 2 diabetes mellitus is increasing throughout the world. Recently, new diagnostic criteria have been established by the American Diabetes Association (ADA), depending on glucose measurements after an overnight fast and after oral glucose loading (1). Because identification of diabetic patients and early treatment is important, these measurements should ideally be performed in the doctor's office, with high accuracy and results rapidly available. Moreover, it has recently been established that aggressive glucose control improves clinical outcome in critically ill patients in intensive care and coronary care units $(2-4)$.
In addition, a growing amount of research is being performed in the area of diabetes, both in the laboratory and in the field. There is therefore an increasing need for an accurate, swift and easy to operate method of glucose determination. Most currently marketed hand-held devices for home glucose determination do not offer sufficient accuracy and precision, especially in the hypoglycemic region, where accurate determination of glucose can be crucial for diagnosis and treatment (5-15). There is no universal agreement on a reference method for glucose determination (16-19). The hexokinase method is frequently used as a reference method in laboratory settings. The glucose oxidase method is frequently used and generally accepted as a standard method when swift glucose readings are 
required, e.g. during glucose clamps. Although quick and proven to be sufficiently accurate in a large range of glycemia, including low values, there are certain disadvantages to the glucose oxidase method, as employed for example in the Yellow Springs Instrument 2300 STAT (YSI). The analyzers are relatively large and non-portable, and interference and technical malfunction can easily occur, they require careful maintenance and can only be operated by trained technicians. The HemoCue Beta-glucose analyzer (HemoCue) is an instrument that uses a dual wavelength photometer to measure glucose in hemolyzed whole blood after a modified glucose dehydrogenase reaction. Because it is portable, it can be used pre-analytically and at the bedside. It requires very little maintenance, its operation is simple and technical malfunction rarely occurs. In previous research, the accuracy of the HemoCue system has been compared with several reference methods. In some studies (20-29) accuracy compared well, whereas in other studies considerable differences were found between HemoCue measurements and the reference method $(5-7,30-36)$. However, several confounding factors could have played a role in the variable results. We aimed to assess the accuracy of the HemoCue and its correlation with the YSI, in particular for hypoglycemic glucose values, using various statistical methods, and correcting for potential biases.

\section{Materials and methods}

Samples were taken from 24 volunteers (14 male and ten female, mean age 43.8 years, range 29.3-67.4), participating in a hyperinsulinemic glucose clamp study that was performed for other purposes. None of the subjects had triglyceride levels $>3 \mathrm{mmol} / \mathrm{l}$ or used ascorbic acid. Average hematocrit was 0.43 (range 0.38-0.51). During the hyperinsulinemic glucose clamp studies, two antecubital veins were cannulated. Insulin and glucose were infused via one cannula. Blood samples from the second cannula in the other arm were arterialized, using a heating sleeve to warm the arm to $55^{\circ} \mathrm{C}$. When withdrawing blood, the first $2 \mathrm{ml}$ were discarded, and immediately thereafter a sample of approximately $1 \mathrm{ml}$ was drawn for analysis. From this sample, a small amount was placed on a sample glass for immediate analysis with a HemoCue $\beta$-glucose system (HemoCue AB, Angelholm, Sweden). As plasma glucose concentrations were required for the clamp studies, the remainder of the blood sample was put into a vial and immediately centrifuged for $15 \mathrm{~s}$ at $5800 \mathrm{~g}$. Subsequently, the glucose level in plasma was analyzed with a glucose oxidase method (YSI 2300 STAT; Yellow Springs Instruments, Yellow Springs, OH, USA). Both instruments were maintained according to the manufacturers' recommendations. Additionally, the YSI was calibrated at the start of every day and after every five samples or a maximum of half an hour, whereas the calibration of the HemoCue was checked before every session with the manufacturer's control cuvette. In addition, the HemoCue's microcuvettes were stored and handled according to the manufacturer's recommendations.

\section{Statistical analysis}

Mean values were calculated and regression analysis was performed. Subsequently, before further analysis the HemoCue results were corrected for the difference in glucose concentration between whole blood and plasma (HemoCue plasma $=1.10$ (HemoCue whole blood)). Plasma glucose concentrations of $<4.2 \mathrm{mmol} / \mathrm{l}$ in the reference method were considered hypoglycemic, in accordance with the guidelines for the blood glucose monitoring systems of the International Organization for Standardization (ISO) (37). This does not necessarily correlate with clinical hypoglycemia. Several different statistical methods were applied to these paired plasma glucose values, analyzing all paired values, as well as the hypoglycemic values separately (plasma glucose in YSI $\leq 4.2 \mathrm{mmol} / \mathrm{l}$ ): (a) mean values; (b) regression analysis; (c) two-tailed Student's $t$-test on mean values of HemoCue and YSI with levels of significance defined as $P<0.05$; (d) percentage of HemoCue values within 5, 10, 15, 20 and $30 \%$ and within $0.2,0.5,0.83,1.0$ and $1.5 \mathrm{mmol} / \mathrm{l}$ of the YSI value respectively; (e) difference between the HemoCue value and the YSI value plotted against the average of the paired values, according to Altman's residuals method (38); (f) error grid analysis (15). Data are presented as means \pm S.E. unless otherwise indicated.

\section{Results}

A total of 500 paired glucose values were obtained, 209 of which were considered hypoglycemic (plasma glucose on YSI $\leq 4.2 \mathrm{mmol} / \mathrm{l}$ ).

Mean HemoCue whole blood glucose was $4.41 \pm 0.004 \mathrm{mmol} / \mathrm{l}$ (range 1.7-14.7), mean YSI plasma glucose was $4.81 \pm 0.004 \mathrm{mmol} / \mathrm{l}$ (range $1.88-$ $1500 ; P=0.001)$. For the hypoglycemic samples, mean HemoCue whole blood glucose was $2.96 \pm 0.003 \mathrm{mmol} / \mathrm{l}$ (range 1.7-4.7), mean YSI plasma glucose was $3.22 \pm 0.003 \mathrm{mmol} / \mathrm{l}$ for YSI (range 1.88-4.20; $P<0.0001)$. Regression analysis showed the following relationship: HemoCue whole blood $=0.9264$ (YSI) $-0.0525 \mathrm{mmol} / \mathrm{l}$, with $r=0.9787$.

After correcting the HemoCue values for the difference between whole blood and plasma glucose concentration, there was no significant difference between the mean values of HemoCue and YSI plasma glucose concentration $\quad(4.85 \pm 0.004$ vs $4.81 \pm 0.004 \mathrm{mmol} / \mathrm{l}$; $P=0.80)$. The relationship with regression analysis 
between these values was HemoCue $=1.019(\mathrm{YSI})$ $-0.0577 \mathrm{mmol} / \mathrm{l}$, with $r=0.9787 \quad$ (Fig. 1). In the hypoglycemic region, mean value after correction was 3.26 $\pm 0.004 \mathrm{mmol} / \mathrm{l}$ for HemoCue (vs $3.22 \pm 0.003 \mathrm{mmol} / \mathrm{l}$ for YSI; $(P=0.59))$. Regression analysis for the hypoglycemic region yielded HemoCue $=1.1169$ (YSI) $\quad-0.3393 \mathrm{mmol} / \mathrm{l}$, with $r=0.8798$ (Fig. 1). The paired plasma glucose values after $10 \%$ correction of the HemoCue whole blood results to HemoCue plasma glucose results were used for further analysis.

The percentage of HemoCue plasma values within relative and absolute margins of the paired YSI values are shown in Table 1. As expected, when all values were considered there were significantly higher percentages within the relative margins mentioned than when only hypoglycemic values were considered. However, there were no significant differences in the percentages of values within the absolute margins, although there was a trend towards higher percentages of hypoglycemic values within the absolute margins.

The plot of the individual differences between YSI and HemoCue against the average of the two measurements showed a difference of $0.03 \pm 0.0009 \mathrm{mmol} / \mathrm{l}$.
For $18(3.6 \%)$ paired values the difference was outside the $95 \%$ limits of agreement $(-0.82-0.89 \mathrm{mmol} / \mathrm{l})$. Plotting the individual differences in the hypoglycemic range showed a difference of $0.04 \pm 0.001 \mathrm{mmol} / \mathrm{l}$. Six $(2.9 \%)$ were outside the $95 \%$ limits of agreement ( $-0.71-0.79 \mathrm{mmol} / \mathrm{l})$ (Fig. 2). When using error grid analysis with YSI values as the reference method, all hypoglycemic HemoCue values except one (99.5\%) were within the clinically accurate zone A (Fig. 3). Of the values $1.4 \%$ were in zone $\mathrm{D}$, possibly leading to a dangerous failure to detect and treat. When plotting all values on the error grid, the same one value was in zone D $(0.2 \%)$ and five values $(1 \%)$ were in zone B, the zone with benign estimate errors. Of all HemoCue values, 98.8\% were within zone A (Fig. 3).

\section{Discussion}

To our knowledge, this is the largest series of paired glucose determinations with the HemoCue system described in the literature, especially for hypoglycemic values. The YSI glucose analyzer, a glucose oxidase system, is currently most frequently used when direct
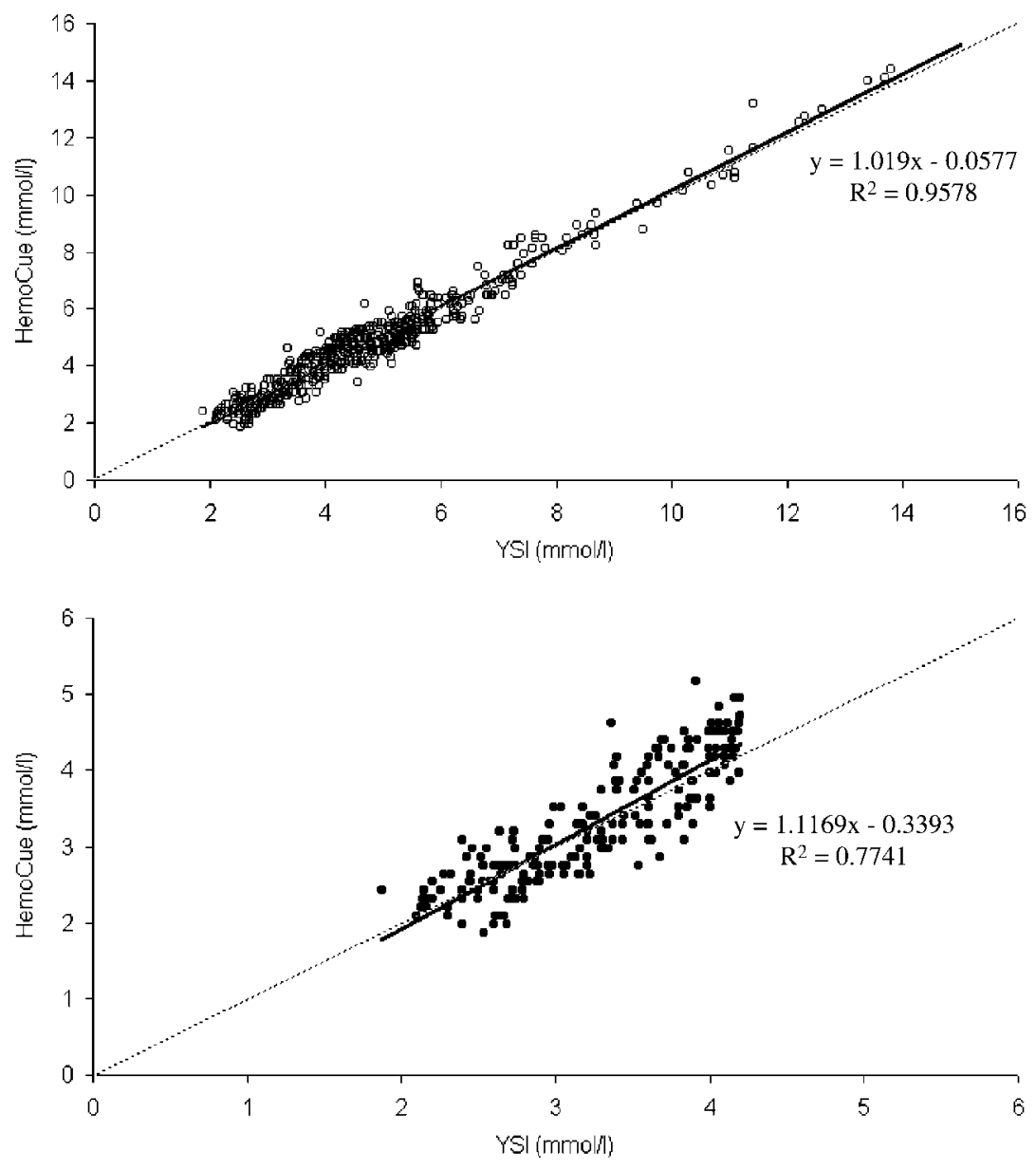

Figure 1 Regression line and regression equation (after 10\% correction for the difference between whole blood and plasma glucose concentration) for all values in the upper panel (open circles) and in the lower panel for hypoglycemic values separately (YSI $\leq 4.2 \mathrm{mmol} / \mathrm{l}$; solid circles). 
Table 1 Percentage of HemoCue plasma values within the margins of the YSI value.

\begin{tabular}{cccl}
\hline Margin & $\begin{array}{c}\text { Hypoglycemic } \\
\text { values (\%) }\end{array}$ & All values (\%) & \multicolumn{1}{c}{$\boldsymbol{P}$} \\
\hline Relative & & & \\
$\pm 5 \%$ & 29.2 & 37.8 & 0.029 \\
$\pm 10 \%$ & 56.9 & 67.4 & 0.0079 \\
$\pm 15 \%$ & 79.9 & 87.4 & 0.01 \\
$\pm 20 \%$ & 92.8 & 96.0 & 0.075 \\
$\pm 30 \%$ & 99.0 & 99.4 & 0.61 \\
Absolute & & & \\
$\pm 0.2 \mathrm{mmol} / \mathrm{l}$ & 35.9 & 32.2 & 0.34 \\
$\pm 0.5 \mathrm{mmol} / \mathrm{l}$ & 79.9 & 75.0 & 0.16 \\
$\pm 0.83 \mathrm{mmol} / /$ & 99.0 & 96.4 & 0.053 \\
$\pm 1.0 \mathrm{mmol} / /$ & 99.0 & 97.8 & 0.26 \\
$\pm 1.5 \mathrm{mmol} / /$ & 100 & 99.8 & 0.51 \\
\hline
\end{tabular}

and accurate determination of glucose concentration is needed, but carries disadvantages in certain situations. We have therefore compared the accuracy of the HemoCue $\beta$-glucose system with the frequently used and well-established YSI 2300 STAT. The HemoCue measures glucose in whole blood after hemolysis, rather than in plasma. However, in research and in most clinical situations, plasma glucose concentrations are generally described. As glucose concentration in plasma is approximately $10-15 \%$ higher than in whole blood, depending on the hematocrit and the method of whole blood analysis $(39,40)$, we applied a conversion factor (1.10) to the paired values before further analysis. This resulted in mean values that were very similar and not statistically significantly different, and in a regression slope very close to 1 . Naturally, the correction had no effect on correlation $(r=0.9787)$. Our finding that correlation was higher in the whole range $(1.9-15.0 \mathrm{mmol} / \mathrm{l})$ than in the hypoglycemic range $(1.9-4.2 \mathrm{mmol} / \mathrm{l})$ was not surprising, as relative margins increase at lower glucose levels, and the coefficient of variation is higher in the lower range of virtually every laboratory test. This effect was enhanced by the fact that the HemoCue displays the result to only one decimal place, whereas the YSI gives three decimal places. It is of note that the relationship between the two methods appeared not to be uniform across the whole range of glucose concentrations. In the lower range, agreement was very close but, for values over $8 \mathrm{mmol} / \mathrm{l}$ and particularly over $11 \mathrm{mmol} / \mathrm{l}$, there was a tendency towards higher results of the HemoCue at higher concentrations. Indeed, this trend can also be observed in some previous studies $(5,22$, 30 ), although it is not clearly present in other studies $(13,24)$. Because the number of measurements is relatively small, the implications are unclear.

We found very small absolute differences between the mean values of HemoCue and YSI, both for all values, in a range from 1.9 to $15.0 \mathrm{mmol} / \mathrm{l}$, and in the hypoglycemic range, which were not statistically significant. However, one has to be aware of the relatively low discriminative power of this test. A more discriminative method of comparison is plotting the differences between the standard method and the test method against the average of the two measurements, according to Altman's residuals

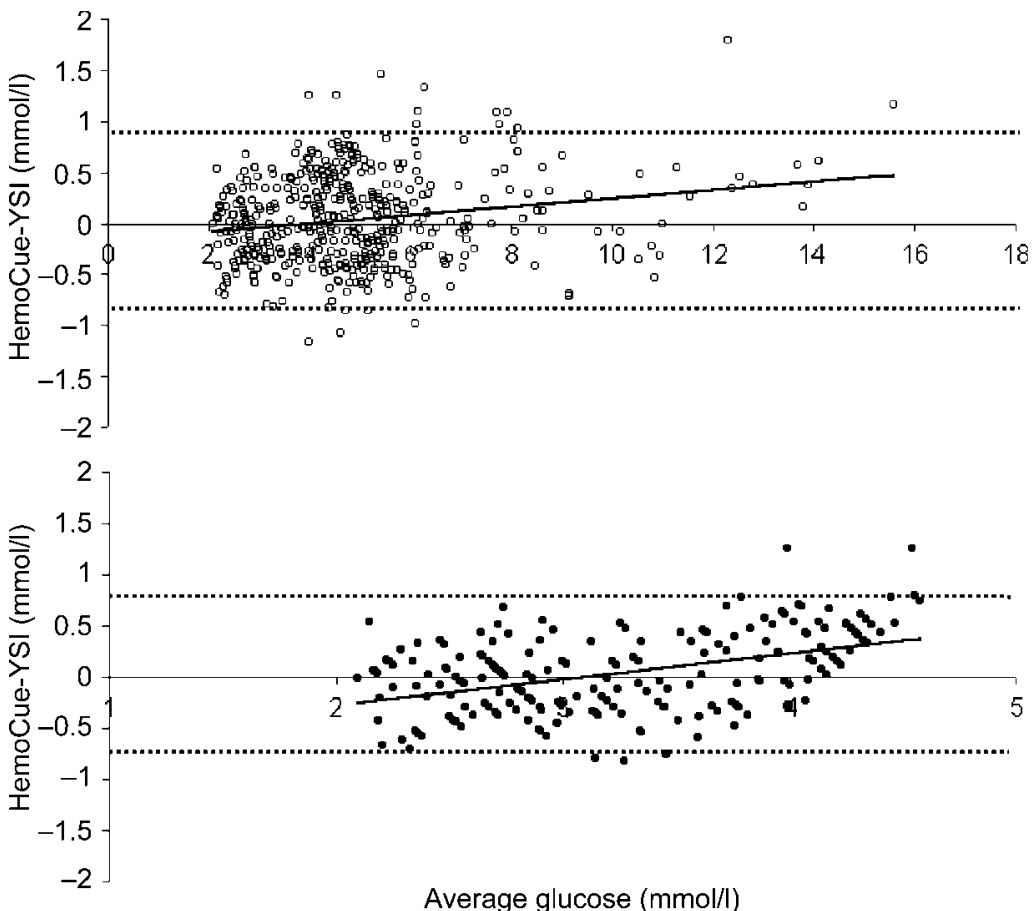

Average glucose $(\mathrm{mmol} / \mathrm{l})$
Figure 2 Altman's residual plot (mean of paired values plotted against the absolute difference between paired values), with $95 \%$ limits of agreement (means \pm 1.96 s.D.; broken lines) and regression line. In the upper panel,

Altman's residual plot of all values (open circles) is shown. For $18(3.6 \%)$ paired values, the difference was outside the $95 \%$ limits of agreement $(-0.82$ to $0.89 \mathrm{mmol} / \mathrm{l})$. The lower panel shows the plot of the hypoglycemic values separately (YSI $\leq 4.2 \mathrm{mmol} / \mathrm{l}$; solid circles). Six $(2.9 \%)$ were outside the $95 \%$ limits of agreement $(-0.71$ to $0.79 \mathrm{mmol} / \mathrm{l})$. 

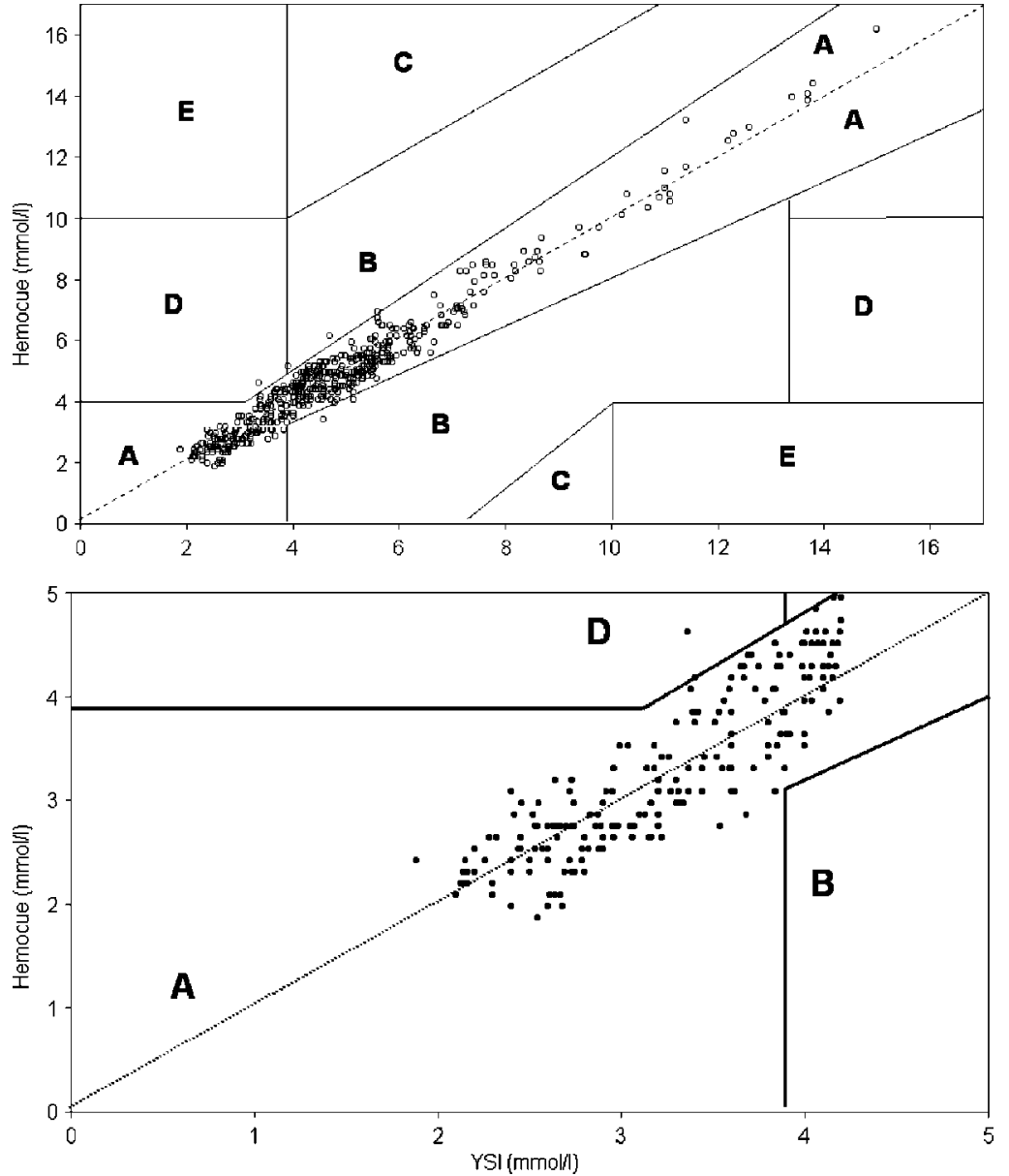

Figure 3 Error grid analysis of the HemoCue plasma glucose concentrations ( $Y$ axes) with the $\mathrm{YSI}$ as reference method (X axes). All values are plotted in the upper panel (open circles); $98.8 \%$ were within the clinically accurate zone A. One value was in zone D $(0.2 \%)$, possibly leading to dangerous failure to detect and treat, and five values were in zone $B$, the zone with benign estimate errors. Error grid analysis for the hypoglycemic values separately (YSA $\leq 4.2 \mathrm{mmol} / \mathrm{l}$; solid circles) are plotted in the lower panel. All hypoglycemic HemoCue values except one $(99.5 \%)$ were within zone A. $1.4 \%$ of the values were in zone $D$. method (38). In the current study, approximately $97 \%$ of all paired measurements were within the $95 \%$ limits of agreement, and also when hypoglycemic values were considered separately. Therefore, the two methods considered in this study agree sufficiently to be used interchangeably (41). Considering these data, one also has to bear in mind that there is no universally agreed reference methodology for blood glucose measurement. All methods used in clinical laboratories and in research show some inaccuracy and variation when compared with each other or to isotope dilution mass spectrometry $(17,29)$.

The criteria recommended by the ADA for home blood glucose measuring devices, stating that all the glucose results of a device should be within $5 \%$ of the reference values (42), have not been met. Considering the discussion on reference values mentioned above, these criteria are very stringent. The International Organization for Standardization (ISO) is more lenient. It proposes that $95 \%$ of measurements should be within $\pm 20 \%$ of the reference method, or within $0.83 \mathrm{mmol} / \mathrm{l}$ for values $\leq 4.2 \mathrm{mmol} / \mathrm{l}$ (37). In this study, the ISO criteria, with YSI as a reference method, are amply met (98.3 and $99.0 \%$ respectively). The recommended criteria of both organizations, however, concern home blood glucose measurements, not laboratory devices.

Error grid analysis was developed by the research group of Cox and Clarke to determine the clinical accuracy of glucose results, taking into account both the difference between the reference and the test method values, and the pertinence of the treatment decision resulting from the test method value $(15,43)$. According to this analysis, only a single HemoCue measurement $(0.2 \%)$ could potentially have led to a dangerous failure to detect and treat hypoglycemia, and five (1.0\%) measurements could have resulted in benign estimation errors. All other measurements (98.8\%) were clinically acceptable. Taking into account the large sample size, these results were clinically very satisfactory.

As mentioned in the Introduction, there has been discussion in the literature about the accuracy of the HemoCue blood glucose measuring device (5-7, 20-36). Several confounding factors could have played a role in the variable results. Sample handling and preservation could have biased the results of certain studies, as samples for HemoCue and for the reference method were handled differently. Determination of glucose concentration at different times after withdrawal of 
blood allows for pre-analytical glucose usage by cells, even when the blood is stored in sodium fluoride, as this does not completely inhibit glycolysis, particularly in the first hours (44). Moreover, several studies compared results from capillary blood with those of venous blood or plasma; these concentrations can differ considerably, especially in the postprandial state (45). In addition, in some studies the authors did not correct the HemoCue results in whole blood to plasma values. Furthermore, a number of, primarily early, studies used statistical methods with low discriminatory power (e.g. regression analysis, coefficient of variation). In nearly all of the studies, there was a low number of hypoglycemic samples. This has been further complicated by the fact that the device has been used a number of times for neonatal hypoglycemic samples, which are from a very specific patient group, different from adults in several ways. Although one study (46) showed no marked effect of hematocrit on glucose measurements presumably, although not mentioned specifically, in adult blood, it is possible that either hematocrit or other factors in neonatal blood have influenced the results (47). When discussing the data provided by studies on blood glucose measurement, we believe that the accuracy and variability of the reference method used should also be taken into account, as there is no generally accepted gold standard, except perhaps for isotope dilution mass spectrometry. Therefore, a discrepancy between two paired measurements of two devices does not necessarily imply that the tested method is inferior to the reference method used.

In the current study, we have used the YSI as the reference method, as it is a frequently used and wellestablished analyzer for immediate and accurate glucose determination in research and clinical applications. On the other hand, it has certain disadvantages, not shared by the HemoCue. We have tried to reduce the confounding factors such as type of blood (capillary vs venous), storage of the samples, delay in measurement and conversion to plasma glucose values. Values in the hypoglycemic region, where inaccuracy is most likely to occur and can potentially lead to dangerous clinical situations, were considered specifically. In addition, various methods of analysis with lower and higher discriminatory power have been used, aiming for assessment of accuracy, and in particular to determine how HemoCue compares with the YSI. This study meets the limitations in its focus on the accuracy itself of the HemoCue. It does not describe correlations between venous glucose concentration as determined by a reference method (or the HemoCue) and capillary glucose concentration measured with the HemoCue. Furthermore, the samples analyzed were from adults with hematocrits within a range of 0.38 to 0.51 . The results cannot be transposed automatically to determinations in samples with higher (or lower) hematocrits or from neonates.
The results of this study have shown that determination of glucose with the HemoCue system has a very high correlation with measurement with the YSI in a broad range of glycemia, and in hypoglycemia in particular. We believe that these methods can be used interchangeably for research and clinical purposes in adults. However, the criteria of the ADA for blood glucose measuring devices were not met. It must be noted that, for reasons discussed, no statements can be made on accuracy in neonates.

\section{Acknowledgements}

This work was supported by a grant from the Dutch Diabetes Research Foundation (no. 96.155). This work is dedicated to the memory of D Willem Erkelens (1941-2004).

\section{References}

1 Expert Committee on the Diagnosis and Classification of Diabetes Mellitus. Report of the Expert Committee on the Diagnosis and Classification of Diabetes Mellitus. Diabetes Care 199720 1183-1197.

2 Van den Berghe G, Wouters P, Weekers F, Verwaest C, Bruyninckx F, Schetz M, Vlasselaers D, Ferdinande P, Lauwers P \& Bouillon R. Intensive insulin therapy in the critically ill patients. New England Journal of Medicine 2001345 1359-1367.

3 Malmberg K, Ryden L, Hamsten A, Herlitz J, Waldenstrom A \& Wedel H. Mortality prediction in diabetic patients with myocardial infarction: experiences from the DIGAMI study. Cardiovascular Research $199734248-253$.

4 Diaz R, Paolasso EA, Piegas LS, Trajer CD, Moreno MG, Corvalan R, Isea JE \& Romero G. Metabolic modulation of acute myocardial infarction. The ECLA (Estudios Cardiologicos Latinoamerica) Collaborative Group. Circulation $1998982227-2234$.

5 Buhling KJ, Henrich W, Kjos SL, Siebert G, Starr E, Dreweck C, Stein U \& Dudenhausen JW. Comparison of point-of-care-testing glucose meters with standard laboratory measurement of the 50g-glucose-challenge test (GCT) during pregnancy. Clinical Biochemistry 200336 333-337.

6 Püntmann I, Wosniok W \& Haeckel R. Comparison of several point-of-care testing (POCT) glucometers with an established laboratory procedure for the diagnosis of type 2 diabetes using the discordance rate. A new statistical approach. Clinical Chemistry and Laboratory Medicine 200341 809-820.

7 Trajanoski Z, Brunner GA, Gfrerer RJ, Wach P \& Pieber TR. Accuracy of home blood glucose meters during hypoglycemia. Diabetes Care $1996191412-1415$.

8 Hawkins RC. Evaluation of Roche Accu-Chek Go and Medisense Optium blood glucose meters. Clinica Chimica Acta 2005353 127-131.

9 Singh Dhatt G, Agarwal M \& Bishawi B. Evaluation of a glucose meter against analytical quality specifications for hospital use. Clinica Chimica Acta $2004343217-221$.

10 Solnica B, Naskalski JW \& Sieradzki J. Analytical performance of glucometers used for routine glucose self-monitoring of diabetic patients. Clinica Chimica Acta 2003331 29-35.

11 Chen ET, Nichols JH, Duh SH \& Hortin G. Performance evaluation of blood glucose monitoring devices. Diabetes Technology and Therapeutics 20035 749-768.

12 Weitgasser R, Gappmayer B \& Pichler M. Newer portable glucose meters - analytical improvement compared with previous generation devices? Clinical Chemistry $1999451821-1825$. 
13 Nichols JH, Howard C, Loman K, Miller C, Nyberg D \& Chan DW. Laboratory and bedside evaluation of portable glucose meters. American Journal of Clinical Pathology $1995103244-251$.

14 Moberg E, Lundblad S, Lins PE \& Adamson U. How accurate are home blood-glucose meters with special respect to the low glycemic range? Diabetes Research in Clinical Practice 199319 239-243.

15 Clarke WL, Cox D, Gonder-Frederick LA, Carter W \& Pohl SL Evaluating clinical accuracy of systems for self-monitoring of blood glucose. Diabetes Care $198710622-628$.

16 Passey RB, Gillum RL, Fuller JB, Urry FM \& Giles ML. Evaluation and comparison of 10 glucose methods and the reference method recommended in the proposed product class standard (1974). Clinical Chemistry 197723 131-139.

17 Björkhem I, Bergman A, Falk O, Kallner A, Lantto O, Svensson L, Åkerlöf E \& Blomstrand R. Accuracy of some routine methods used in clinical chemistry as judged by isotope dilution-mass spectrometry. Clinical Chemistry 198127 733-735.

18 Gerson B \& Figoni MA. Clinical comparison of glucose quantitation methods. Archives of Pathology and Laboratory Medicine $1985109711-715$.

19 Pelletier O \& Arratoon C. Precision of glucose measurements in control sera by isotope dilutio $\mathrm{n}$ mass/spectrometry: proposed definitive method compared with a reference method. Clinical Chemistry 198733 1397-1402.

20 Steige H, Hanson E, Lisko L \& Burritt MF. Evaluation of the HemoCue blood glucose system. Clinical Chemistry 199238 (Suppl) 1048.

21 Bitzén P-O, Olsson S, Tryding N \& Scherstén B. HemoCue, a new instrument capable of analysing blood glucose with high precision. Diabetologia 199134 (Suppl) A174.

22 Voss EM \& Cembrowski GS. Performance characteristics of the HemoCue B-glucose analyzer using whole-blood samples. Archives of Pathology and Laboratory Medicine $1993117711-713$.

23 Ashworth L, Gibb I \& Alberti KGMM. HemoCue: evaluation of a portable photometric system for determining glucose in whole blood. Clinical Chemistry 199238 1479-1482.

24 Rassam AG, McLeod J, Burge MR \& Schade DS. Use of the HemoCue blood glucose analyzer in research studies. Diabetes Care 199821 1369-1370.

25 Genter PM \& Ipp E. Accuracy of plasma glucose measurements in the hypoglycemic range. Diabetes Care 199417 595-598.

26 M'Bemba J, Chevalier A, Bruzzo F, Slama G \& Selam JL. Usefulness of the HemoCue blood glucose photometer in hypoglycaemic conditions. Diabetic Medicine 199714711.

27 Vadasdi E \& Jacobs E. HemoCue $\beta$-glucose photometer evaluated for use in a neonatal intensive care unit. Clinical Chemistry $1993392329-2332$.

28 Schlebusch H, Niesen M, Sorger M, Paffenholz I \& Fahnenstich H. Blood glucose determinations in newborns: four instruments compared. Pediatric Pathology and Laboratory Medicine 199818 $41-48$.

29 Hannestad U \& Lundblad A. Accurate and precise isotope dilution mass spectrometry method for determining glucose in whole blood. Clinical Chemistry 199743 794-800.

30 Torjman MC, Jahn L, Joseph JI, Crothall K \& Goldstein BJ. Accuracy of the HemoCue portable glucose analyzer in a large nonhomogenous population. Diabetes Technology and Therapeutics $20013591-600$.
31 Young RP, Critchley JAJH, Lau MSW, Lee KKC, Robertshaw AM, Chan TYK \& Anderson DC. Reliability of glucose measurement using the HemoCue analyser in hypoglycaemia. Annals of Clinical Biochemistry 199431 573-575.

32 Leonard M, Chessall M \& Manning D. The use of a HemoCue blood glucose analyser in a neonatal unit. Annals of Clinical Biochemistry $199734287-290$.

33 Sharief N \& Hussein K. Comparison of two methods of measurement of whole blood glucose in the neonatal period. Acta Paediatrica $1997 \mathbf{8 6} 1246-1252$.

34 Deshpande SA, Matthews JNS \& Ward Platt MP. Measuring blood glucose in neonatal units: how does HemoCue compare? Archives of Diseases in Childhood 199675 F202-F208.

35 Brunner GA, Ellmerer M, Sendlhofer G, Wutte A, Trajanoski Z, Schaupp L, Quehenberger F, Wach P, Kresj GJ \& Pieber TR. Validation of home blood glucose meters with respect to clinical and analytical approaches. Diabetes Care 199821 585-590.

36 Elimam A, Horal M, Bergström M \& Marcus C. Diagnosis of hypoglycaemia: effects of blood sample handling and evaluation of a glucose photometer in the low glucose range. Acta Paediatrica $199786474-478$.

37 International Organization for Standardization, Requirements for in vitro blood glucose monitoring systems for self-testing in managing diabetes mellitus. ISO/TC 212/WG 3. In Draft International Standard ISO/DIS 15197. Geneva, Switzerland: ISO 2001.

38 Bland JM \& Altman DG. Statistical methods for assessing agreement between two methods of clinical measurement. Lancet $1986327307-310$.

39 Caraway WT \& Watts NB. Carbohydrates. In Textbook of Clinical Chemistry, pp 784-789. Ed. N Tietz. Philadelphia, PA: WN Saunders Co., 1986.

40 Burrin JM \& Alberti KGMM. What is blood glucose: can it be measured? Diabetic Medicine 19907 199-206.

41 Bland JM \& Altman DG. Comparing methods of measurement: why plotting difference against standard method is misleading. Lancet 1995346 1085-1087.

42 American Diabetes Association, Self monitoring of blood glucose (Consensus Statement). Diabetes Care 199619 (Suppl 1) S62-S66.

43 Cox DJ, Gonder-Frederick LA, Kovatchev BP, Julian DM \& Clarke WL. Understanding error grid analysis. Diabetes Care 199720 911-912.

44 De Pasqua A, Mattock MB, Phillips R \& Keen H. Errors in blood glucose determination. Lancet $1984 \mathbf{3 2 4} 1165$.

45 Kuwa K, Nakayama T, Hoshino T \& Tominaga M. Relationships of glucose concentrations in capillary whole blood, venous whole blood and venous plasma. Clinica Chimica Acta $20013 \mathbf{3 0 7}$ 187-192.

46 Wiener K. An assessment of the effect of haematocrit on the HemoCue blood glucose analyser. Annals of Clinical Biochemistry $19933090-93$.

47 Zijlstra WG, 't Hart N \& Baarsma R. The Hemocue B glucose analyser and neonatal blood glucose monitoring. (Letter to the Editor). Annals of Clinical Biochemistry 199835330.

Received 18 February 2005

Accepted 19 April 2005 